\title{
An ethnographic exploration of knowledge practices within the Queensland Music Festival
}

\section{Acknowledgements}

The authors would like to thank the Queensland Music Festival for enabling access and supporting the research process.

\begin{abstract}
Purpose - The purpose of this article is to examine the utilisation and application of reflexive ethnography as an interpretative methodology for researching knowledge practices within festival organisations.

Design/methodology/approach - The ethnographic approach incorporates two methods of data collection in the research design; participant observation and indepth interviews.

Findings - The research identified that knowledge management practices and processes are often invisible to festival staff when they are embedded within a cohesive organisational culture. Ethnography enables the researcher to make explicit the tacit and normalised ways of working that contribute to the success (and failure) of festival organisations to manage knowledge. The immersion of the researcher in the ethnographic process provided a rich understanding of the relational dimension of knowledge management that would be difficult to elicit from in-depth interviews alone.
\end{abstract}

Research limitations/implications - New fields of study require a range of research methodologies to inform theoretical and practice based knowledge related to event participation and management. This article contributes to the growing event management literature through a unique focus on ethnography as a research method that offers a deeper understanding of knowledge practices within festival organisations.

Originality/value - Limited research has applied an ethnographic approach to festival and event management. This article builds upon early adopters and provides critical insight into the benefits and constraints of ethnographic research. 
Keywords: ethnography, qualitative research methods, knowledge practices, Australia

Article classification: Research paper

\section{Introduction}

The proliferation of events research over the last decade has resulted in a growing body of literature that utilises a range of research methods. However, quantitative research has been dominant in the field and the lack of qualitative and interpretivist methods has been identified as problematic for both the events and knowledge management literatures (Magalhaes, 1998, Kane et al., 2005, Holloway et al., 2010). In this article the authors examine the utilisation and application of a reflexive ethnographic methodology to investigate the culture and organisational practices shaping knowledge management within Drag Queen'sLand, an event held under the Queensland Music Festival (QMF) organisational umbrella. Knowledge management is an under explored aspect of festival processes that identifies the organisation's capacity “to create new knowledge, disseminate it throughout the organization, and embody it in products, services and systems" (Nonaka and Takeuchi, 1995, p. 3).

The research design is informed by a post-structuralist framework that emphasises how the management of festival knowledge is constructed through a multiplicity of perspectives, roles and organisational power relationships (Alvesson and Skoeldberg, 2000). We draw upon the common classification of knowledge management into domains that relate to technological, organisational or relational dimensions (Schuett, 2003, Heisig, 2009). As we have argued elsewhere (X, in press) a relational perspective is important for understanding the collaborative and intense nature of festival work and management. The pulsating nature of festival organisations creates challenges for organisers who must develop, store and transfer knowledge across dynamic staff teams that fluctuate over the event lifecycle 
(Hanlon and Cuskelly, 2002). In order to understand more deeply the nature of such challenges, the first author immersed herself in the festival organisation as an ethnographer, being an insider and outsider at once. Two methods of data collection informed the ethnography: participant observation and in-depth semistructured interviews. Undertaking these two methods over a period of several months helped to track changes within the festival life cycle and to identify changes in the organisational culture over time (Lewis, 2003), which was essential to understanding how knowledge practices and shared meanings were created between festival members (Benton and Craib, 2001).

The article aims to contribute to the event literature on qualitative research applications in festival management, and we begin with an exploration of the research literature on ethnography. Second, the article specifically focuses on challenges relating to knowledge management and the role of ethnography in understanding knowledge processes and practices. Third, the QMF festival organisation and the research process are discussed. Fourth, key findings are outlined in relation to the Drag Queen'sLand performance and implications for festival research are discussed in light of the ethnographic approach. We draw upon interview transcripts as well as the extensive field notes and research diary as a chain of evidence to track changes in meaning throughout the festival life cycle, and to identify different perspectives on knowledge management. Finally, the article concludes with a discussion of the merits and challenges faced by qualitative event researchers who seek to reflexively engage with an ethnographic methodology. In addition, we reflect upon the research dilemmas and limitations of ethnography, as well as its potential to inform new theoretical approaches within the events field.

\section{Ethnographic Research}

Qualitative research methodologies allow researchers to gain insight into the lived experiences of their participants, thus producing rich, descriptive material that may facilitate a more nuanced understanding of cultures, meanings and perspectives. An interpretive perspective seeks to more deeply explore how people make sense of their social world (Denzin, 1997). As a particular interpretative approach, 
ethnography allows researchers to become highly involved and immersed in the social world of their participants. Atkinson and Hammersley (1994, p. 248) suggest that ethnography incorporates several key elements: exploring the nature of a particular social phenomena; working with "unstructured" data; investigating a small number, or just one case, in detail with explicit interpretation of the meanings.

Ethnography is a research approach that is utilised extensively within the social science disciplines of anthropology and sociology (Roberts and Sanders, 2005) and has also begun to inform the applied fields of management (Schultze, 2000, Carlile, 2002, Van Maanen, 2011), education (Vaughan, 2004, Tsolidis, 2008), tourism (O'Gorman et al., 2012), as well as sport, event and leisure studies (Cohen, 1993, Sparkes, 2009, Noy, 2011, Fullagar and Pavlidis, 2012). The value of the ethnographic approach is that it is uniquely placed to access the cultural world of research participants, in this case festival organisers and producers. By studying people within their natural, or organisational, settings an ethnographic approach "enables researchers to explore both the structures and interactions within their cultural context, and the meanings that participants give to their cultural environment" (Holloway et al., 2010, p. 75). This 'insider' reflexivity is critical to the development of theoretical insights into unique festival processes, particularly the effect of organisational culture on the relational knowledge management of festival organisations.

Ethnographic research prioritises the perspectives of those being studied, which is achieved through researchers experiencing and engaging within the participants' setting. The researcher spends an extended period of time with participants, observes and participates in day-to-day practices and key events, and becomes fully immersed in the culture of the organisation (Kellehear, 1993, Brewer, 2000, Humphreys et al., 2003, Sjoestedt Landen, 2011). Observation can be conducted in an overt or covert manner, meaning that either all participants know about the researcher's presence or the researcher's identity is concealed. Either way, the challenge for the participant observer is to maintain a balance between their 'insider' and 'outsider' perspective. Corbin Dwyer and Buckle (2009, p. 61) argue that the researcher needs to occupy the "space between" and constantly move between the 
two poles of being an insider and outsider. These dual perspectives help make explicit the detailed pattern of social relationships and organisational culture. In addition, 'critical outsiders', such as other research collaborators, can also assist in balancing these dual perspectives, enabling problems observed as an insider to be discussed and assessed from another perspective (Lofland et al. 2006).

To become an 'insider' the researcher needs to establish close relationships with the participants, but at the same time maintain a certain distance in order to be able to professionally observe and collect the data (Vinten, 1994, Ashworth, 1995, Lofland et al., 2006, Davies, 2008). O’Reilly (2005, p. 93) argues that, “[p]eople can alter their behaviour when someone new enters the scene, but they can only keep this up for a short time. When you have hung around long enough you become part of the setting, part of the background that others are taking for granted." Thus it is important to spend sufficient time with the organisation under study and to document the process of becoming immersed in the field. An important part of ethnographic research data collection is the practice of writing field notes (Bogdan, 1972). Field notes are written through the researcher's observation of events, descriptions of settings, as well as their own reflection upon participants' experiences, concerns and meanings (Emerson et al., 1995). Furthermore, by taking field notes the researcher can recount his or her own experience of becoming a member of the organisation through the process of acquiring organisational knowledge. Taking field notes over a long period of time also allows the researcher to track changes in organisational culture and behaviour across the festival life cycle (Bogdan, 1972, Emerson et al., 1995, Lofland et al., 2006).

Immersion within a research setting also allows the researcher to utilise multiple methods, which can offer insight into different perspectives and meanings. As Getz (2008) and Holloway et al. (2010) argue academic legitimacy can only be established when there is diversity evident in data collection and analysis methods. Participatory observation, field notes, interviews and textual analysis are research methods commonly utilised by ethnographers (O'Reilly, 2005) to identify the known and unknown, visible and invisible aspects of culture. Therefore, through ethnographic research an in-depth understanding of the unspoken, assumed or 
'tacit' dimension of knowledge is possible (Kane et al., 2005). Ethnographic research offers a means of making an organisation's tacit knowledge explicit, as the "ethnographer 'inscribes' social discourse; he (sic) writes it down" (Geertz, 1973, p. 19). In this sense, Geertz (1973) argues that the processes of observing and writing ethnography are mediated by language and hence it is acknowledged that research is not simply a representation of the 'real' but a storied practice.

In spite of the depth of meaning that can be garnered from well-designed qualitative methodologies, such as ethnography, quantitative research remains dominant in the festival and events management field. However, as Getz et al. (2010, p. 51) note, "[f]estival and event management will gain enormously from experimental and field methods aimed at greater understanding of experiences and meanings." $\mathrm{A}$ relatively new research approach within festival and event settings (Holloway et al., 2010, Fullagar and Pavlidis, 2012), ethnography has predominantly been used to study the festival experience (Cummings, 2007). Much of this research has focussed upon the experiential nature of those social groups and participants attending and/or participating in events rather than the organisational culture and festival management.

In response to the call for more qualitative ethnographic studies in event management (Cummings, 2007, Holloway et al., 2010, Duffy et al., 2011, Fullagar and Pavlidis, 2012), this research focuses on an organisational case study of how QMF manages and interprets knowledge practices as a key aspect of culture. Case study research is commonly used for ethnographic research to provide a context (Brewer, 2000). The advantage of case studies is that they are bound in time and place, with clear delineations, similar to the temporal and spatial nature of events. Findings produced from case study research present a 'snapshot' of a phenomena at a point in time. Such findings are not generalised, instead the focus is on describing and analysing particular social relationships and organisational issues to produce greater understanding. This is particularly pertinent for knowledge management research as often there is little explicit identification and articulation of knowledge practices at both an individual and organisational level (Ives et al., 2000, Orlikowski, 2002). An ethnographic research methodology can assist re- 
searchers to make visible aspects of festival culture that have been largely invisible or tacit forms of knowledge within organisational practices and management approaches.

\section{Examining knowledge practices: Challenges for festival organisations}

Knowledge management has been recognised as one area that can be utilised by organisations to gain competitive advantage (Nonaka, 1994). However, the creation, dissemination and effective management of knowledge within organisations is complex. A variety of knowledge management models have emerged; and these provide ideas about how to improve the identification, creation, transfer, and documentation of knowledge (Heisig, 2009). These processes of managing knowledge help organisations to learn over time, and build upon what has or has not worked in the past (Argyris and Schoen, 1978, Senge, 2006). Effective knowledge management, which includes the creation of new knowledge, the transfer of knowledge within the organisation and the embodiment of this new knowledge in products, services and systems (Nonaka and Takeuchi, 1995), is an important requirement for both creativity and innovation (Carlsen et al., 2010). Of particular importance is the creation and transfer of tacit knowledge (the 'assumed' and unspoken knowledge about how things work in an organisation) as it cannot be easily documented or stored in databases and checklists (Polanyi, 1966, reprinted 1983, Nonaka and Von Krogh, 2009).

While a comprehensive analysis of the current knowledge management literature would be beyond the scope of this article, we found that ethnographic methods are still under utilised in knowledge management research despite their potential to more fully uncover the tacit knowledge existent in organisations (Kane et al., 2005). Ethnographic methods enable the researcher to become deeply embedded within the organisation to gain a snapshot of organisational culture, structures and relationships. What is less able to be defined or articulated from such immersion is a detailed understanding of key knowledge practices without the direct involvement in this festival work. 
In terms of knowledge management research, therefore, ethnography helps us understand the processes and practices of establishing knowledge relations and ways of working with others, collaborating and transferring knowledge (Orlikowski, 2002, Kane et al., 2005). Ethnography offers the researcher an insider perspective that also facilitates a deeper understanding of the organisational culture and how knowledge management occurs. Several authors have argued that the organisational culture greatly influences knowledge sharing behaviour (e.g., Connelly and Kelloway, 2003, Yang, 2007, Suppiah and Singh Sandhu, 2011). To understand the organisation as an insider enables the researcher to build the same kind of relationships and trust that employees need to build in order to be able to work together and to acquire a shared understanding, as well as to participate and thus learn from experience. Dixon (1999, p. 201) maintains, "[m]uch of the organization's culture is learned gradually, over time, and without the conscious intent of either the new or existing members." An ethnographic approach is well-suited to accomplish this learning experience and to enable the acquisition of both explicit and tacit forms of organisational knowledge. These experiences form important aspects of knowledge practices which cannot be fully understood from interviews alone. At the same time, reflection on knowledge management issues through an outsider perspective is also important. Due to the collective construction of meaning in organisations (Dixon, 1999, Holmberg, 2000) the outsider role is important in opening up dialogue, bringing in new ideas and challenging existing meaning through the process of asking questions and having employees reflect on their professional practices. Such reflections frequently occur through informal conversations in the everyday organisational setting rather than in formal interviews and can thus be made explicit through ethnographic research.

Magalhaes (1998, p. 99) summarised the concern of many researchers in the field of knowledge management and organisational learning by stating that, "not nearly enough attention is being given to interpretivist and qualitative methods, including narrative and language-based research." Alvesson and Kaerreman (2001, p. 1015) further argue that " $[\mathrm{u}]$ nderstanding knowledge, not as objective facts and causal explanations, but as a situated, community-based set of meanings, may bring the epistemological outlook in knowledge management more up-to-date". Ethnograph- 
ic studies on knowledge management have been conducted by Schultze and Boland (2000), Orlikowski (2002), Carlile (2002), as well as Koh et al. (2005). The main focus of these studies is on knowledge practices, or 'knowledge in practice', highlighting the human actions and relations in knowledge practices as opposed to merely dealing with information management and knowledge documentation. In addition, Orlikowski (2002, p. 255) argues that ethnographic data can offer "more grounded accounts of work practices".

Festival organisations are somewhat unique in terms of their knowledge management needs, which is an under researched area. Within an event context, the pulsating nature of festival organisations necessitates that knowledge is transferred and communicated between a wide range of stakeholders within short time periods. Too often, there are knowledge gaps, or the loss of knowledge occurs as individuals enter or exit the organisational environment. In particular, a more detailed examination is needed of the relational aspect of festival cultures where collaboration and the creation of new knowledge occur within short timeframes. To operate effectively, within defined and tight time periods, festival organisations need to understand what contributes to effective knowledge management processes and strategies. Through ethnographic research these knowledge practices and relational aspects of knowledge management can be uncovered and made explicit.

To date the main focus of knowledge management research within the festival and event management body of knowledge, has been on understanding knowledge as an asset that requires storage and documentation as part of the event evaluation process (Allen et al., 2011, Getz, 2012). However, knowledge management also needs to be understood as a dynamic process and ongoing practice that occurs throughout the entire festival life cycle. The history, context and culture of an organisation play a significant role in effective knowledge management (Suppiah and Singh Sandhu, 2011, Wang et al., 2011). We argue from a post-structural perspective that the connection between power and knowledge also needs to be made explicit in the organisational context: "It is not possible for power to be exercised without knowledge, it is impossible for knowledge not to engender power" (Foucault, 1980, p. 52). Hence, the study that is the focus of this article sought to 
use an ethnographic approach to examine how knowledge management was practiced and interpreted in the dynamic context of a festival organisation's culture.

\section{An Ethnography of the Queensland Music Festival: Drag Queen'sLand Produc- tion}

\section{Research context}

The Queensland Music Festival (QMF) is a 17 day long biennial music festival incorporating a range of performances, events and productions that take place in Brisbane and a host of regional communities throughout Queensland. The vision for the QMF is to "transform lives through unforgettable musical experiences" (QMF, 2011). The festival is managed by a permanent staff of seven people and supported by another 35 production, administrative and marketing professionals, as well as over 2,000 international, national and community-based artists during each festival season (QMF, 2011). It thus represents an organisational structure typical of festivals, and faces the challenge of bringing festival members with various backgrounds together for a short period of time. However, QMF differs in terms of the multiple performances, locations and communities with whom they collaborate to produce the festival. In terms of knowledge management, the QMF can be regarded as a 'unique case' characterised by dispersed knowledge relations that are embedded in particular knowledge management practices and embodied by the permanent and seasonal staff. The first author gained approval from the QMF executive director, QMF board of directors and University Human Ethics Committee to conduct the ethnographic research with the festival organisation as a case study.

Implementing the vision requires QMF staff to balance the inclusion of a range of music styles performed by professionals, with the imperative to encourage community participation in the arts. As we have previously identified ( $\mathrm{X}$, in press), "many artistic projects held in the communities are long-term collaborations that tell local stories and define local culture". As a former QMF director Terracini (2007, p. 24) also suggests that, "[i]f the work you create is not intrinsically connected to the culture of that place, it will not resonate." In this article we explore 
the value of ethnography as an interpretative method that enables deeper understanding of organisational culture and knowledge practices. We focus on one production, Drag Queen'sLand, as a project commissioned and presented by QMF in 2011. Drag Queen'sLand was an urban arts theatre production about the challenges and issues of being a drag queen in Queensland (a State with an historically hostile relationship with the queer community). The piece was created by two writers and two composers, as well as a dramaturge and a designer, and was planned over a one year period. Managed from the QMF office in Brisbane, with one of the teams (a producer, technical manager and project coordinator) being mainly responsible for the show, meetings usually took place at the festival office. The rehearsals started approximately three weeks before the show, but collaborative meetings with the drag community and production meetings started much earlier.

The actual performance was staged with three professional actors. The main reason for employing actors rather than drag queens related to QMF's aim to interpret the complex experience of being a drag queen in Queensland. Nevertheless, the drag community felt some level of ownership of the piece as they collaborated in every major decision along the way and contributed not only their stories but also advice and help during the creative development process. There were a total of seven shows between 15 July and 23 July 2011. The shows were presented at the Judith Wright Centre in a cabaret style setting with a small stage in the middle of the room that was surrounded by several tables. The performance created a very intimate atmosphere. The three actors were on stage all the time, even costume changes were made on stage as part of the show, because it was argued that this is an important part of performing the drag queen identity. Additionally, two musicians were sitting next to the stage playing live. The performance was a ticketed event with marketing material emphasizing that it was an 18 year+ event containing "violence, adult themes, nudity, offensive language and theatrical smoke effects" (QMF brochure, 2011).

\section{Research design and methods}

The study is part of a larger research project on knowledge management and festival organisational culture. The interpretative design of the ethnographic research 
process required the first author to become immersed within the QMF festival organisation in order to understand the culture from the 'inside'. Overt participant observation of the organisational culture of the Queensland Music Festival was undertaken over a period of 8 months (January 2011 - August 2011). Board members, staff members and volunteers of the organisation consented to the research and the researcher's presence, in order to make transparent the observation and encourage participation. Participation involved attending staff meetings, workshops, concerts, and other key events before, during, and after the festival. The researcher also frequently assisted with small jobs, such as data entry, ticket allocations, mass emails, or follow-up phone calls in order to contribute to the festival organisation. Lofland et al. (2006) argued that in ethnographic research it can be difficult for the researcher to step back and critically assess the observations and that fellow researchers may act as 'outsiders' with whom these problems can be discussed. The second and third authors took on this 'outsider' role to enable critical reflexivity throughout the research process.

Field notes were taken at times during, and more commonly after, all observations. These field notes include descriptions of different settings, events, participants and the festival atmosphere, as well as informal discussions with festival members. The field notes also describe the process of becoming a member of the festival organisation and acquiring organisational knowledge. Revisiting these field notes allowed us to critically reflect on earlier observations and to identify changes in the researchers' as well as participants' perceptions and meaning. As a collaborative project the authors were able to move between positions as insiders and outsiders to facilitate interpretative analysis and the identification of key themes.

A total of 28 in-depth interviews were conducted with a range of the event's stakeholders, whom held different positions or responsibilities, from long-term staff members as well as newcomers. A method of "purposive sampling" was used to assure that participants "have particular features or characteristics which will enable detailed exploration and understanding of the central themes and puzzles which the researcher wishes to study" (Ritchie et al., 2003, p. 78). In this particular project we focussed on the participants' different experiences and roles within the 
festival organisation. Of these 28 interviews two respondents were members of the Drag Queen'sLand production team and five members of the festival staff provided further insights into the broader context of this project within QMF. Participation in interviews was completely voluntary, with some interviews occurring prior, others during or after the festival in order to cover the temporal dimension of the festival.

Additionally, textual and visual information from the QMF organisation website, festival programme, meeting minutes, emails and other texts were also collected. These data were examined to contextualise research participants' responses and to articulate, or make visual, the creation of the festival identity and culture. As part of the festival discourses these data sources were important to understand the discursive levels of meaning that shapes festival management (Hall, 1997a, McKee, 2003). The transcribed interviews, field notes and other texts were stored and analysed using Nvivo qualitative software (Bazeley, 2007). A thematic analysis was undertaken to explore key aspects of knowledge management and the QMF organisational culture. The findings offer an interpretation of the multiple experiences and meanings through the ethnographer's own insights and reflections. Our final interpretation of the organisational culture and the effect on knowledge management and individual's meaning is, however, not the only 'true' interpretation and definitive account; rather it is one possible production of meaning based on the available information, context and our personal backgrounds (Seale, 1999, Saukko, 2003, Snape and Spencer, 2003, Guba and Lincoln, 2005).

\section{Findings}

\section{Knowledge practices that build relationships and trust}

Drag Queen'sLand demonstrated the complexity of different layers of cultural understanding evident in knowledge management research. Firstly, QMF needed to build relationships with the Brisbane drag community to ensure they supported the piece. Creating a working partnership between the festival organisation and the community is a key element of community arts programmes (Adam and Goldbard, 2001). Festival staff and community members are partners in the project and need to learn to work together over a long period of time. Initial rapport has to 
be built and strong relationships based on trust and mutual respect of cultural differences need to be maintained with certain members of the community who may act as gatekeepers (Phipps and Slater, 2010). Learning to understand each other is crucial throughout the process and developing these partnerships and relationships takes time as festival staff members have to meet frequently with members of the community to discuss and negotiate the process of creative development (Hager, 2008). Knowledge has to be transferred frequently and easily, so that both partners have the opportunity to continuously learn from each other.

For the Drag Queen'sLand project, QMF used a thorough process of building relationships with the Brisbane drag community to gain the community's approval, trust and support to ensure they 'owned' the piece. One participant recounted how she approached key contacts within the community:

First day I arrived, I started ringing drag queens, literally... and looking them up on Facebook. That's where I started which is kind of random but it seemed like the easiest place to start. And also not only was it just finding the drag queens, but it was also connecting to the venues where they perform, and to their networks, and liaising with the people in those networks, getting them to support the project and know that we were doing it - again - with integrity and authenticity. And that it was about a real portrayal, not something frivolous or taking advantage or anything like that. So lots of the networks that we liaised with came on board as supporters or sponsors or whatever. (interview, 16/08/11)

For this participant it was clear from the beginning that the project needed support not only from drag queens themselves, but from a much broader network of people. The QMF team had to build and maintain good working relationships with all these stakeholders throughout the process. In essence QMF engaged in a form of ethnographic research themselves as they sought to identify, create and translate knowledge about the drag queen culture. In approaching the gatekeepers of this community, the staff member needed to provide as much information about the project as possible and explain that QMF was going to honestly represent the community in the show in order to get them to support the piece. The practice of 
identifying and approaching them came forward as a crucial activity as part of building relationships and knowing the players in the game.

The first author witnessed several occasions in which QMF staff members enacted the above described practice of building relationships with members of the drag community. She identified that this practice was a crucial aspect of the embodied tacit knowledge that staff members possessed about approaching the community with respect in order to collaborate on the piece. In her role as an ethnographic researcher the first author also experienced the relationship building process with members of the staff as well as with members of the community, which at times meant she needed to step back and remain an outsider in order to avoid assuming that she 'knew' the community,

Elisa and Curtis then have another meeting, I don't know with whom. I am too scared to ask whether I can join them. After I know now how complicated the politics are in this community, I need to be careful. As long as I can observe some meetings at the office and then maybe later once rehearsals start, that's fine. I think it's inappropriate for me to just walk in and sit-in the meeting today though. It's hard to tell, but since it is a very complicated project and difficult topic, I do not want to interfere unless they tell me it's okay to observe. (field notes, 08/06/11)

With the sensitivity to the range of cultural differences (professional culture, drag culture, academic culture) there was a need to be cautious and balance the ethnographic desire to become an insider whilst remaining an outsider during the early stages of participant observation. It is evident that the establishment of trust and respect of difference was integral to building the relationships and understanding the knowledge practices that enabled the production and for the ethnographic research to occur. Going through a similar process of building relationships and trust enabled the ethnographic researcher to understand staff members' embodied knowledge practices. The ethnographic research approach enabled the researcher to build and develop these relationships over time, which assisted the understanding and interpretations of knowledge that other qualitative research methods would have been unable to solicit. 
Knowledge practices in co-creating the performance

Community arts projects are co-created with the community. The community's input is regarded as crucial and important, as it is their story that is being told (Kay, 2000, Adam and Goldbard, 2001). Relationships, as discussed above, need to be maintained throughout in a process of collaboration, between the festival staff and the community, for pieces and performances to be co-created. The community needs to be included in all major decisions, for example changes in the script.

Compounding the complex knowledge relationships within the Drag Queen'sLand production was a major production challenge for the event itself - the drag queens were not performing their stories on stage but were rather represented by three professional actors. Therefore, it was difficult at times to gain the community's approval, trust and support and to ensure that they felt they had actually co-created the piece. The QMF staff and the event creative team engaged in a thorough consultative process to ensure accurate and sensitive representations of this 'other' culture.

We did that the whole way, like "what do you think of the script? What do you think of this script? What do you think of the music? Here is your story... it's been realised as a poetic piece of music, like a poem and music fusion. And this was a very tragic moment that happened to you, or a really dark thing that happened to you... What do you think of it? Do you want us to scrap it?" So there was always this sort of consultation of putting things in front of them and pulling it back. (interview 27, 16/08/11)

As this collaborative process is informed by the core principles of the festival, the first author paid particular attention to situations in which the practice of cocreation was enacted. In one of the meetings (field notes, 15/06/11), for example, it became apparent that the drag king community felt excluded from the project and the producer decided to include an exhibition of drag queen and king costumes prior to the show, because "it was important that we reflected and paid homage to the people who this show is about and whose stories were there" (interview 27, 16/08/11). This decision demonstrated QMF's respect for, and how they gained the trust and support from, the drag community. For the ethnographer it was im- 
portant to not only ask staff members in formal interviews, but also to experience collaboration and co-creation between QMF and the drag community first hand in order to understand the practice of knowing how to work with the community as it is embodied by QMF staff members. Furthermore, going through a similar process in relation to the ethnographic research, we acknowledge that this research is cocreated in the interpretative relationships within the research team (reflexive dialogue between insiders and outsiders) and also with the QMF.

Through the open dialogue and consultative process, the drag community felt ownership of the piece and were proud that their stories were told. This was an important learning experience for the QMF staff and a shared practice that can be built on in future events with other communities or in other locations throughout Queensland (Orlikowski, 2002). Staff members reflected upon how they needed to engage in this consultation process with every community they worked with, no matter how much or how little they were involved in the final performance on stage. Therefore, these 'relational' knowledge practices (Holmberg, 2000, Orlikowski, 2002) have been made explicit and hence can be shared within the organisation and applied to future community arts projects included in the QMF.

It is crucial to understand the different relations of power during the project development process and to effectively deal with the different wants and desires of each group. The practices of collaborating and co-creating the piece constitute 'knowing how' to work with the community, which is crucial for festival staff in order to be able to follow the QMF principles and values and to create new knowledge together with the community. The QMF emphasis therefore was not on the creation of a drag show, but rather "a show that investigates the humanity of drag, why people do this, what their motivators are, what their drivers are" (interview, 12/07/11). The show was advertised as, "See the unofficial queens of Queensland in a psychological burlesque act" (Courier Mail, 23/07/11). Making these tacit and relational knowledge practices visible would be challenging if another research method had been utilised. The immersion of the researcher and the reflexive process of ethnography were critical to understand the co-creative knowledge practices of the QMF. 


\section{Knowledge practices in representing 'others'}

As soon as the rehearsals for Drag Queen'sLand started, the creative team and actors encountered a further challenge. The three professional actors had the necessary performance experience; however, they did not feel they had the authority to represent drag queens who essentially are performers themselves, because "they can say, "why can't I just do it? I'm a performer, why can't I just do it?!" (interview 13, $12 / 07 / 11)$. Balancing authenticity with the need to stage an event was discussed by one member of the creative team:

It's very difficult. They knew a lot about it even before we went into the creative development, it was really important that they understood the politics between the artists in the room. (...) And one of the key things that they all said was that they felt very uncomfortable playing drag queens. They didn't feel as if they had the authority to do the work. There was a fundamental block at first day of rehearsal! And I think that's fantastic that they articulated that. We met with the drag queens at the end of the first week and after they had met with them, there was a much stronger sense that... because it's like they have given their blessing to be able to do this. (interview 13, 12/07/11)

This key moment, for the actors, was crucial in assisting the actors to become 'insiders to the community and feel more comfortable with who they were to represent. The experience also mirrors the complex relational process that ethnographers undergo to feel as though they are 'authentically' part of the festival organisation. The first author found at times she did not feel comfortable being part of the Drag Queen'sLand project even though she had been invited by QMF to study it. It took her several weeks and informal discussions to come to understand both the actors and drag queens, but she never became a true 'insider' to this project. However, after spending sufficient time with the organisation, coming to understand the culture of QMF, it was possible to narrate their insights through the research.

The relational understanding of knowledge management was crucial to the success of the Drag Queen'sLand event. At an organisational level, the QMF acknowledged that they were effectively the conduit between the drag queen culture and the mainstream urban arts performance. Taking the time to get to know each other 
through meetings and discussion helped them understand and learn from each other. On an individual level, sharing their feelings, emotions and knowledge enabled all parties to develop trust, respect and reciprocity. This was evident at the conclusion of the event:

On the final night after the show finished everybody who was involved in the show went down to the Wickham Hotel, where all of the main drag queens who contributed to the show, whose voices you heard and whose outfits were represented in the exhibition, they all performed that night at the Wickham [Hotel]. So they came to our show and then we went to theirs and it was a really good way... well, the director said, "We're closing the loop." It did really feel like that. They invited the actors up on stage and then they had a kind of moment homage to each other, which was really really nice. It felt good; it felt like it was the right thing to do. Well, it WAS in the best sense of the world, because it felt like we had successfully integrated and brought the two things together, if that makes sense?! (interview 27, 16/08/11)

Adopting an ethnographic perspective assisted the researcher in identifying how knowledge was managed in a highly sensitive, relational way in a controversial event production. In addition, QMF was itself actively engaged in a form of ethnographic research in order to produce an event that represented the drag queen culture to a wider audience. Understanding the knowledge practices and power relations inherent in representing 'others' through performance was a crucial part of effectively working with the drag community. Ethnographic researchers may never become 'insiders' due to different cultural identities and hence the importance of emphasising partial understanding and analytic insights rather than a universalised theories of festival dynamics.

\section{Discussion}

Qualitative methodologies offer researchers a variety of approaches to gaining valuable insight into the world of those being studied. Ethnography is one particular approach that can contribute to furthering empirical and theoretical understandings of event participation and management practices. Our research into the knowledge practices that produced the QMF Drag Queen'sLand event has revealed 
insights about both organisational and research processes. The three themes that were identified in the findings reveal the complex knowledge practices that are crucial to building relationships, co-creating the performance and representing 'others' as well as the role of the ethnographer in making them explicit. There were clear parallels in the research between the 'relational' knowledge management approach in the QMF organisation and the relational context of ethnographic practices that seek to observe, write and reflect upon another culture (Atkinson and Hammersley, 1994, Holmberg, 2000, Alvesson and Kaerreman, 2001). Both management and research domains offered challenges about how to engage with different cultures, build trust and establish mutual respect as the condition for understanding and collaboration (Coffey, 1999, Holliday, 2007, Sjoestedt Landen, 2011). Knowledge sharing and the generation of insight were key outcomes and an essential part of the process of creating a theatrical performance and enabling the performance of research. Undertaking ethnographic research mirrored similar knowledge practices of building relationships with those under study, co-creating the research and representing 'others'. Ethnography in the context of event organisations has a different focus to that of event participation as the researcher needs to become part of a professional festival culture (Schultze, 2000). The credibility and acceptance of the researcher relies heavily on their ability to become immersed in the organisational vision, work practices and timelines in a way that is seen to 'add value' by those being studied.

The value the ethnographic approach utilised in this research was the depth of insight into how participants within an event organisation and the organisation itself identify, create, transfer and translate their own and others knowledge. The success of the Drag Queen'sLand project as an urban project required a professional practice of working with the community to facilitate the creative development process. Constant reference to the core "principles" or vision of the festival enabled a sensitive engagement with, and representation of, the lives of others in often marginalised communities. Hence, the management of this festival event reflected a strong community cultural development ethos which aimed to "make the invisible more visible and give voice to those who are rarely heard; leading to more open discourses on how to reduce social exclusions" as well as "help to make people 
more open-minded and less fearful of unknown 'others'" (Mulligan and Smith, 2006, p. 48-49). Open dialogue about the creation of events, rather than imposing

events 'upon' a community underpins the sense of ownership (Reid, 2007). Our research also revealed the practical 'research' process that festival and event organisations undertake in order to engage with and learn from different cultures in order to tell their 'stories'. It is evident that the depth of insight into the facets of knowledge management practiced by the QMF organisation and staff would not have been elicited from interviews alone. The observational process of immersion enabled the researcher to crystallize many tacit organisational knowledge practices that were not self evident to festival staff despite their importance.

\section{Conclusion}

Unlike quantitative research that measures knowledge within an organisation the ethnographic research utilised within this study has demonstrated that the tacit and relational dimension of organisational knowledge is often difficult to identify and articulate. A significant outcome of this research was the identification of the complexity of knowledge practices within a festival organisation that highlighted how professionals implemented the QMF vision through community engagement and creative collaboration. Parallels were also found between the process of ethnographic research and knowledge management in the key themes presented in the findings; building relationships, co-creating the performance and acknowledging the dilemmas of knowing the 'other' through research and festival production. There are implications arising from this research for other event and festival organisations related to the importance of valuing the often invisible tacit and relational aspects of knowledge management (open dialogue and consultative processes).

Even with the most thorough checklists, detailed information management systems and sophisticated online communication, large, multifaceted arts festivals will fail to achieve their vision without a culture that supports collaboration and knowledge sharing in everyday professional practice. Through the research process the QMF staff were able to reflect upon what aspects of knowledge manage- 
ment contributed to the festival success that had not been clearly recognised in the past and may help to strengthen the future strategic direction. An important part of the QMF's approach to knowledge management was forward planning and hence the investment of time and funds to enable relationships and trust to develop with communities. In the contemporary context of a competitive event environment and fiscal constraint, there are also implications for funding bodies and festival managers who operate within shorter time frames that may limit reflective learning, relationship building and knowledge sharing (Orlikowski, 2002). In this article we have presented the value of ethnographic research for festival organisations and we have made the case for the academic contribution to knowledge of festival management. In terms of future directions we suggest a greater focus on collaboration between academic researchers and festival managers who seek to continuously improve their management practices and innovative programming. One strategy that festivals could employ to inform their development as learning organisations would be to host an 'ethnographer in residence'. Ethnographic research offers a means of creating deeper understanding of how festival cultures, and academic research about festivals, are continually shaped through interpretive processes (Law, 2004).

\section{References}

Adam, D. and Goldbard, A. (2001), Creative Community - The Art of Cultural Development, The Rockefeller Foundation, New York.

Allen, J., O’Toole, W., McDonnell, I. and Harris, R. (2011), Festival and Special Event Management, John Wiley \& Sons Ltd, Milton, Qld.

Alvesson, M. and Kaerreman, D. (2001), “Odd Couple: Making Sense of the Curious Concept of Knowledge Management”, Journal of Management Studies, Vol. 38 No. 7, pp. 995-1018.

Alvesson, M. and Skoeldberg, K. (2000), Reflexive Methodology - New Vistas for Qualitative Research, SAGE Publications, London/Thousand Oaks/New Delhi. 
Argyris, C. and Schoen, D. (1978), Organizational Learning: A Theory of Action Perspective, Addison-Wesley Publishing Company, London et al.

Ashworth, P.D. (1995), “The Meaning of "Participation" in Participant Observation”, Qualitative Health Research, Vol. 5 No. 3, pp. 366-387.

Atkinson, P. and Hammersley, M. (1994), "Ethnography and Participant Observation”, in Denzin, N.K. and Lincoln, Y.S. (Ed.), Handbook of Qualitative Research. SAGE Publications, pp. 248-261

Bazeley, P. (2007), Qualitative Data Analysis with NVivo, SAGE Publications, Los Angeles/London/New Delhi/Singapore.

Benton, T. and Craib, I. (2001), Philosophy of Social Science - The Philosophical Foundation of Social Thought, Palgrave, Houndmills/Basingstoke/Hampshire/New York.

Bogdan, R. (1972), Participant Observation In Organizational Settings, Syracuse University Press, Syracuse.

Brewer, J.D. (2000), Ethnography, Open University Press, Buckingham/Philadelphia.

Carlile, P.R. (2002), “A Pragmatic View of Knowledge and Boundaries: Boundary Objects in New Product Development", Organization Science, Vol. 13 No. 4, pp. 442-455.

Carlsen, J., Andersson, T.D., Ali-Knight, J., Jaeger, K. and Taylor, R. (2010), “Festival management innovation and failure", International Journal of Event and Festival Management, Vol. 1 No. 2, pp. 120-131.

Coffey, A. (1999), The Ethnographic Self: fieldwork and the representation of identity, SAGE Publications, London/Thousand Oaks/New Delhi.

Cohen, S. (1993), "Ethnography and popular music studies", Popular Music, Vol. 12 No. 2, pp. 123-138. 
Connelly, C.E. and Kelloway, E.K. (2003), "Predictors of employees' perceptions of knowledge sharing cultures", Leadership \& Organization Development Journal, Vol. 24 No. 5, pp. 294-301.

Corbin Dwyer, S. and Buckle, J.L. (2009), “The Space Between: On Being an InsiderOutsider in Qualitative Research", International Journal of Qualitative Methods, Vol. 8 No. 1, pp. 54-63.

Cummings, J. (2007), Sold Out! An Ethnographic Study of Australian Indie Music Festivals, Doctor of Philosophy Doctoral Thesis, University of Western Sydney.

Davies, C.A. (2008), Reflexive Ethnography - A Guide To Researching Selves And Others, Routledge, London and New York.

Denzin, N.K. (1997), Interpretive Ethnography - Ethnographic Practices for the 21st Century, SAGE Publications, London.

Dixon, N.M. (1999), The Organizational Learning Cycle - How We Can Learn Collectively, Gower, Hampshire and Vermont.

Duffy, M., Waitt, G., Gorman-Murray, A. and Gibson, C. (2011), "Bodily rhythms: Corporeal capacities to engage with festival spaces", Emotion, Space, Society, Vol. 4 No. 1, pp. 17-24.

Emerson, R.M., Fretz, R.I. and Shaw, L.L. (1995), Writing Ethnographic Fieldnotes, The University of Chicago Press, Chicago and London.

Foucault, M. (1980), Power/Knowledge - Selected Interviews \& Other Writings 19721977 (edited by Gordon, C.), Pantheon Books, New York.

Fullagar, S. and Pavlidis, A. (2012), “'It's all about the journey': Women and cycle tour events", International Journal of Event and Festival Management, Vol. 3 No. 2, pp. 149-170. 
Geertz, C. (1973), The Interpretation of Cultures - Selected Essays, Basic Books Inc, New York.

Getz, D. (2008), "Event Tourism: Definition, evolution, and research", Tourism Management, Vol. 29 No. 3, pp. 403-428.

Getz, D. (2012), "Event Studies: Discourses and Future Directions", Event Management, Vol. 16 Vol. 2, pp. 171-187.

Getz, D., Andersson, L. and Carlsen, J. (2010), "Festival management studies Developing a framework and priorities for comparative and cross-cultural research", International Journal of Event and Festival Management, Vol. 1 No. 1, pp. 29-59.

Guba, E.G. and Lincoln, Y.S. (2005), "Paradigmatic Controversies, Contradictions, and Emerging Confluences", in Denzin, N.K. and Lincoln, Y.S. (Ed.), The SAGE Handbook of Qualitative Research, 3rd ed, SAGE Publications, Thousand Oaks/London/New Delhi, pp. 191-215.

Hager, L.L. (2008), “Community Arts”, in Carpenter, G. And Blandy, D. (Ed.), Arts and Cultural Programming - A Leisure Perspective, Human Kinetics, Champaign et al., pp. 159-172.

Hall, S. (1997), “The Work of Representation”, in Hall S. (Ed.), Representation Cultural Representations and Signifying Practices. SAGE Publications, London/Thousand Oaks/New Delhi, pp. 13-74.

Hanlon, C. and Cuskelly, G. (2002), "Pulsating Major Sport Event Organizations: A Framework for Inducting Managerial Personnel”, Event Management, Vol. 7, pp. 231-243. 
Heisig, P. (2009), "Harmonisation of knowledge management - comparing $160 \mathrm{KM}$ frameworks around the globe", Journal of Knowledge Management, Vol. 13 No. 4, pp. 4-31.

Holliday, A. (2007), Doing and writing qualitative research, SAGE Publications, London/Thousand Oaks.

Holloway, I., Brown, L. and Shipway, R. (2010), "Meaning not measurement - Using ethnography to bring a deeper understanding to the participant experience of festivals and events", International Journal of Event and Festival Management, Vol. 1 No. 1, pp. 74-85.

Holmberg, R. (2000), “Organizational learning and participation: Some critical reflections from a relational perspective", European Journal of Work and Organizational Psychology, Vol. 9 No. 2, pp. 177-188.

Humphreys, M., Brown, A.D. and Hatch, M.J. (2003), "Is Ethnography Jazz?”, Organization, Vol. 10 No. 1, pp. 5-31.

Ives, W., Torrey, B. and Gordon, C. (2000), "Knowledge Sharing Is a Human Behavior", in Morey, D., Maubury, M. and Thuraisingham, B. (Ed.), Knowledge Management - Classic and Contemporary Works, The MIT Press, Cambridge, MA and London, pp. 99-129.

Kane, H., Ragsdell, G. and Oppenheim, C. (2005), "Knowledge Management Methodologies", in Remenyi, D. (Ed.), 2nd International Conference on Intellectual Capital, Knowledge Management and Organisational Learning, Dubai, 2005, Academic Conferences Limited, pp. 253-266.

Kay, A. (2000), “Art and community development: the role the arts have in regenerating communities", Community Development Journal, Vol. 35 No. 4, pp. 414-424. 
Kellehear, A. (1993), The Unobtrusive Researcher - A Guide to Methods, Allen \& Unwin.

Koh, S.C.L., Gunasekaran, A., Thomas, A. and Arunachalam, S. (2005), "The application of knowledge management in call centres", Journal of Knowledge Management, Vol. 9 No. 4, pp. 56 - 69.

Law, J. (2004), After Method - mess in social science research, Routledge, London and New York.

Lewis, J. (2003), "Design Issues", in Ritchie, J. and Lewis, J. (Ed.), Qualitative Research Practice: A Guide for Social Science Students and Researchers SAGE Publications, London/Thousand Oaks/New Delhi, pp. 47-76.

Lofland, J., Snow, D., Anderson, L. and Lofland, L.H. (2006), Analyzing Social Settings - A Guide to Qualitative Observation and Analysis, Thomson Wadsworth, Belmont, CA.

Magalhaes, R. (1998), “Organizational Knowledge and Learning”, in Von Krogh, G., Roos, J. and Kleine, D. (Ed.), Knowing in Firms - Understanding, Managing and Measuring Knowledge, SAGE Publications, London/Thousand Oaks/New Delhi, pp. 87-122.

McKee, A. (2003), Textual Analysis - A Beginner's Guide, SAGE Publications, London/Thousand Oaks/New Delhi.

Mulligan, M. and Smith, P. (2006), "Stepping Out of the Shadows of Neglect - Towards an understanding of socially applied community art in Australia", International Journal of the Arts in Society, Vol. 1 No. 4, pp. 43-52.

Nonaka, I. (1994), “A Dynamic Theory of Organizational Knowledge Creation”, Organization Science, Vol. 5 No. 1, pp. 14-37. 
Nonaka, I. and Takeuchi, H. (1995), The Knowledge Creating Company - How Japanese Companies Create the Dynamics of Innovation, Oxford University Press, New York.

Nonaka, I. and Von Krogh, G. (2009), “Tacit Knowledge and Knowledge Conversion: Controversy and Advancement in Organizational Knowledge Creation Theory", Organization Science, Vol. 20 No. 3, pp. 635-652.

Noy, C. (2011), “The Aesthetics of Qualitative (Re)search: Performing Ethnography at a Heritage Museum”, Qualitative Inquiry, Vol. 17 No. 10, pp.917-929.

O’Gorman, K.D., MacLaren, A.C. and Bryce, D. (2012), “A call for renewal in tourism ethnographic research: the researcher as both the subject and object of knowledge", Current Issues in Tourism, iFirst article, pp. 1-14.

O’Reilly, K. (2005), Ethnographic Methods, Routledge, London and New York.

Orlikowski, W.J. (2002), "Knowing in Practice: Enacting a Collective Capability in Distributed Organizing”, Organization Science, Vol. 13 No. 3, pp. 249-273.

Phipps, P. and Slater, L. (2010), "Indigenous Cultural Festivals - Evaluating Impact on Community Health and Wellbeing”, RMIT University, Melbourne: Globalism Research Centre.

Polanyi, M. (1966, reprinted 1983), The Tacit Dimension, Peter Smith, Gloucester, MA. QMF (2011), “Queensland Music Festival”, available at http://qmf.org.au/ (accessed 20 September 2011).

Reid, S. (2007), "Identifying Social Consequences for Rural Events", Event Management, Vol. 11, pp. 89-98.

Ritchie, J., Lewis, J. and Elam, G. (2003), "Designing and Selecting Samples", in Ritchie, J. and Lewis, J. (Ed.), Qualitative Research Practice: A Guide for 
Social Science Students and Researchers, SAGE Publications, London/Thousand Oaks/New Delhi, pp. 77-108.

Roberts, J.M. and Sanders, T. (2005), "Before, during and after: realism, reflexivity and ethnography", The Sociological Review, Vol. 53 No. 2, pp. 294-313.

Saukko, P. (2003), Doing Research in Cultural Studies - An introduction to classical and new methodological approaches, SAGE Publications, London/Thousand Oaks/New Delhi.

Schuett, P. (2003), "The post-Nonaka Knowledge Management", Journal of Universal Computer Science, Vol. 9 No. 6, pp. 451-462.

Schultze, U. (2000), “A Confessional Account of an Ethnography about Knowledge Work", MIS Quarterly, Vol. 24 No. 1, pp. 3-41.

Schultze, U. and Boland, R.J. (2000), "Knowledge management technology and the reproduction of knowledge work practices", Journal of Strategic Information Systems, Vol. 9, pp. 193-212.

Seale, C. (1999), The Quality of Qualitative Research, SAGE Publications, London/Thousand Oaks/New Delhi.

Senge, P.M. (2006), The Fifth Discipline - The Art and Practice of the Learning Organization, Random House Business Books, London.

Sjoestedt Landen, A. (2011), "From ethnographic 'self'-discovery to processes of identification", Qualitative Research, Vol. 11 No. 5, pp. 536-551.

Snape, D. and Spencer, L. (2003), "The Foundations of Qualitative Research", in Ritchie, J. and Lewis, J. (Ed.), Qualitative Research Practice: A Guide for Social Science Students and Researchers, SAGE Publications, London/Thousand Oaks/New Delhi, pp. 1-23. 
Sparkes, A.C. (2009), "Ethnography and the senses: challenges and possibilities", Qualitative Research in Sport and Exercise, Vol. 1 No. 1, pp. 21-35.

Suppiah, V. and Singh Sandhu, M. (2011), “Organisational culture's influence on tacit knowledge-sharing behaviour", Journal of Knowledge Management, Vol. 15 No. 3, pp. 462-477.

Terracini, L. (2007), A Regional State of Mind - Making Art Outside Metropolian Australia, Currency House, Strawberry Hills, NSW.

Tsolidis, G. (2008), “The (im)possibility of poststructuralist ethnography - researching identities in borrowed spaces", Ethnography and Education, Vol. 3 No. 3, pp. $271-281$

Van Maanen, J. (2011), "Ethnography as Work: Some Rules of Engagement”, Journal of Management Studies, Vol. 48 No. 1, pp. 218-234.

Vaughan, K. (2004), "Total Eclipse of the Heart? Theoretical and ethical implications of doing post-structural ethnographic research", Discourse: Studies in the Cultural Politics of Education, Vol. 25 No. 3, pp. 389-403.

Vinten, G. (1994), "Participant Observation: A Model for Organizational Investigation?", Journal of Managerial Psychology, Vol. 9 No. 2, pp. 30-38.

Wang, D., Su, Z. and Yang, D. (2011), “Organizational culture and knowledge creation capability", Journal of Knowledge Management, Vol. 15 No. 3, pp. 363-373.

Yang, J.-T. (2007), “Knowledge sharing: Investigating appropriate leadership roles and collaborative culture", Tourism Management, Vol. 28, pp. 530-543. 